\title{
Religious Involvement, the Serotonin Transporter Promoter Polymorphism, and Drug Use in Young Adults
}

\author{
Rachel E. Dew ${ }^{1}$ \& Harold G. Koenig ${ }^{1,2}$ \\ ${ }^{1}$ Department of Psychiatry and Behavioral Sciences, Duke University Medical Center, Durham, North Carolina \\ ${ }^{2}$ Department of Medicine, King Abdulaziz University, Jeddah, Saudi Arabia \\ Correspondence: Harold G. Koenig, M.D., Department of Psychiatry and Behavioral Sciences, Box 3400 Duke \\ University Medical Center, Durham, North Carolina 27710, USA. E-mail: Harold.Koenig@duke.edu
}

Received: October 12, 2013 Accepted: October 27, 2013 Available online: November 6, 2013

doi:10.11114/ijsss.v2i1.235 URL: http://dx.doi.org/10.11114/ijsss.v2i1.235

\begin{abstract}
We examine whether the genetic basis for religious involvement is common to the genetic basis for drug use/abuse, helping to explain the inverse relationship between religiosity and drug use. To test this hypothesis, we analyzed data on 2,537 young adult siblings participating in Wave III of the National Longitudinal Study of Adolescent Health on whom both genetic characteristics and religious participation were collected. Religion/spirituality was assessed with four measures: frequency of attendance at religious services and other religious youth meetings, frequency of private prayer, self-rated importance of religion and spirituality, and self-reported history of a life-changing spiritual experience. Each religious measure was examined individually and combined together into a summary scale. Illicit drug use (including prescription drug abuse) was assessed. Polymorphisms of the promoter region of the serotonin transporter gene, SLC6A4 (i.e., LL, SL, SS genotypes) were determined. Results indicated that (1) all religious measures were inversely related to drug use/abuse, (2) the SLC6A4 genotypes $S S$ and $S L$ were less common among those who were more religious, especially among non-whites, and (3) SS/SL genotypes were less common among those who used illegal drugs. Despite being less likely to have the protective SS/SL genotype, religious adolescents were still less likely to use drugs. (4) There was no evidence that the serotonin transporter genotype mediated the relationship between religiosity and illegal drug use. These findings suggest that genetic factors play a role in religiosity, especially in non-whites, and that both genotype and religiosity independently predict substance abuse.
\end{abstract}

Keywords: religion, adolescents, polymorphism, serotonin, addiction, illegal and illicit drugs

\section{Introduction}

\subsection{Background}

Much controversy surrounds the role of the serotonin transporter promoter polymorphism, 5-HTTLPR, in psychiatric illness. This genetic locus, also called SLC6A4, can have short $(S)$ or long $(L)$ sequences of variable number tandem repeats (VNTRs) which encode for less or more of the serotonin transporter protein, respectively. In a landmark study, Caspi and colleagues (2003) reported a connection between the $S$ allele of SLC6A4, stressful life events, and the development of depression. Since then, SLC6A4 gene locus has been the subject of numerous studies, many of which found correlations of the 5-HTTLPR short allele to unfavorable mental health outcomes: these include depression (Brown \& Harris, 2003), anxiety (Minelli et al., 2011), obsessive compulsive disorder (Atmaca et al., 2011), eating disorders (Calati et al., 2011), and substance use (Gerra et al., 2004; Kogan et al., 2010; Merenakk et al., 2011).

\subsection{Literature Review}

This literature, like many subfields within psychiatric genomics, is plagued by non-replication and heterogeneity (Karg et al., 2011). Two distinct meta-analyses of the topic have recently drawn opposite conclusions on whether the connection of SLC6A4 to life stress and depression is supported (Karg et al., 2011; Risch et al., 2009). Problems of this kind likely reflect complexity in the relationship of the human genome to behavioral health outcomes. Even if measurement error in the outcomes themselves could be eliminated, it would be naive to discount additive, mediational, and moderating influences from the environment. This is reflected in the study of 
how social factors, previously implicated in mental illness, relate to candidate genes in modeling psychiatric outcomes.

One pervasive social influence often linked with mental health is religious involvement (Koenig et al., 2012). Although variously measured as attendance at religious services, self-rated importance of spiritual issues, frequency of private prayer or meditation, or dependence on religious beliefs in times of stress, religious involvement has been found repeatedly to relate inversely with negative outcomes such as depression and all types of substance abuse (Dew et al., 2008). These effects have been demonstrated in many cultures, religious groups, and across the life cycle (Koenig et al., 2012). Mechanisms underlying these findings have not been fully clarified. Many studies show that the salutary effects of religious involvement on depression can be partially explained by health behaviors and social support; however, these factors rarely account for all of religion's apparent effect (George et al., 2002). Furthermore, the most well documented finding, that substance use is lower in religious persons, has not been explored much in terms of mechanism (Edlund et al., 2010). Although it may be assumed that proscriptive teachings explain part of this connection, the effect is often observed with regard to un-proscribed substances (Michalak et al., 2007).

How religious involvement as an important environmental factor relates to genotype is not clear. Some studies have found religiosity to interact with genetic risk, moderating the inherited tendency to bad outcomes (Beaver et al., 2009; Timberlake et al., 2006; Kendler \& Myers, 2009). Another question to consider, however, is to what extent religiosity is itself genetically determined. Several studies have isolated heritable components (Nilsson et al., 2007; Vance et al., 2010; Koenig et al., 2007). In this vein, "effects" of religiosity on health could be partially or fully explained as resulting from a common underlying genetic substrate.

Given the consistent relationship of religiosity to substance abuse and the possible heritable nature of both, shared genetics may help to explain the correlation. However, studies of molecular genetics examining relationships of religion to substance abuse are few (Beaver et al., 2009; Nilsson et al., 2007). The current study, designed to address this gap in the literature, utilizes data from a large cohort of younger adults to explore relationships among common candidate genes, use of illicit drugs, and religious beliefs and behaviors. Data on common genetic polymorphisms, including those of the SLC6A4 gene, were collected from a subsample of approximately 2,500 individuals.

\subsection{Hypotheses}

We hypothesized that: (a) religious involvement will be inversely related to illicit drug use, (b) religious involvement will correlate with the presence of polymorphisms of the SLC6A4 gene, (c) drug use will correlate with polymorphisms of the SLC6A4 gene, and (d) the SLC6A4 genotype will at least partially explain the relationship between religiosity and drug use.

\section{Method}

\subsection{Design and Sample Recruitment}

The National Longitudinal Study of Adolescent Health ("Add Health") is a prospective study of a nationally representative cohort of Americans from early adolescence through adulthood. Methods of sampling, data collection, as well as bio-specimen collection, DNA extraction and analysis have been described elsewhere (Guo et al., 2006). The present study utilized de-identified data from a subsample of participants who had blood collected for genotyping, consisting of approximately 2537 monozygotic and dizygotic twins, full and half siblings, unrelated step siblings, and independent unrelated subjects. Genetic data, as well as information on drug use, religiosity, and relevant covariates, were drawn from Wave 3, when subjects were 18-26 years old.

\subsection{Measures and Covariates}

Religiosity was assessed using four measures and a scale that combined these four measures into a single index: frequency of attendance at religious services (religious attendance and attendance at youth group functions), self-rated importance of religion and spirituality (four questions asking about self-assessed religiousness/spirituality and importance of religiousness/spirituality), frequency of private prayer (single question), and self-reported history of a life-changing religious experience (single question). These religious variables include the most commonly studied constructs in the religion/health literature (Koenig et al., 2012). Depressive symptoms and antisocial behaviors (delinquency) were included as psychosocial controls. Depression was operationalized as a continuous variable, a composite of responses to 13 items drawn from the Center for Epidemiological Studies Depression Scale (CES-D) (Roberts \& Vernon, 1983). Delinquency was assessed by a summation of responses to 13 items asking about criminal and violent behavior, excluding substance use. Drug use was conceptualized as endorsing any use of illicit drugs during the seven years since the previous data collection. This measure included prescription drugs taken without a doctor's permission, as this is 
a rising trend in substance abuse. Race was analyzed based on a single variable, white vs. non-white $(1,0)$. This more simplistic measure was chosen due to the significant overlap seen in racial and ethnic categories in this cohort, where a large number of subjects endorsed multiple categories. Genotype with regard to SLC6A4 was coded 1 if either allele included the short coding polymorphism ( $S S$ or $S L$ ), and 0 if both alleles consisted of the long coding polymorphism $(L L)$.

\subsection{Statistical Analyses}

All analyses were performed using SAS Enterprise Guide 5.1 (Cary, NC). Contingency tables were constructed and bivariate analyses conducted to assess relationships among all variables. Relationships between religiosity measures and SLC6A4 were tested using multivariable models controlled for demographics. For this preliminary analysis no attempt was made to account statistically for paired data due to twin or sibling status or the larger study's clustered design.

Initial analyses evaluated the relationship between religiosity and the serotonin transporter gene. Demographic effects initially modeled included age, race, parental education level, and gender; however, gender and parental education showed no significant relationship to SLC6A4 genotype and were subsequently dropped. Each of the five religious variables was entered into separate models due to the high inter-correlations between measures of religiosity. Possible explanatory variables (depression and delinquency scores) were added subsequently. Given the known relationship of this genotype to race (Gelernter et al., 1997) and variation in religiosity among races (Chatters et al., 2009), a religiosity X race interaction term was added to the model in the final stage.

Logistic regression models were then constructed predicting use of illicit drugs since the previous data collection ( $1=$ yes, $0=$ no). A base model of illicit drug use predicted by race, gender, age, and parental education was created. To this model, each of the five religious variables was sequentially added and examined independently. SLC6A4 genotype was then added to each model to assess for possible mediation. Potential psychosocial mediators (depression and delinquency) were added next. Finally, interaction terms between religiosity and SLC6A4 genotype were added to the models, to assess for any interrelationship between these variables.

\section{Results}

\subsection{Characteristics of Sample}

There were a total of 2,537 participants who had data on both genotype and religiosity. The sample was nearly equally divided by gender (52\% female), was predominantly white $(72 \%)$, and had a mean age of 22 years (range 18-26). Average parental education level was 3 years post-secondary school.

\subsection{Bivariate Analyses}

Bivariate statistics indicated significant correlations between race and presence of $S$ allele ( $S S$ and $S / L$ ) of the SLC6A4 genotype, i.e., the SS/SL genotype was more common in whites than non-whites (Table 1). Consistent with previous literature, all measures of religious/spiritual involvement were stronger in female subjects and in non-whites, and measures of illicit drug use were consistently lower in females and in non-whites. As expected, all religious variables correlated significantly and inversely with all measures of substance abuse. Finally, the $S$ allele was also correlated with all five religious variables such that subjects with the genotype $S S$ or $S L$ had lower levels of religiosity (Table 2).

\subsection{Multivariate Analyses}

Initial multivariable analysis controlled for race, age, gender, and parental education; however, gender and parent education were not related to SLC6A4 genotype and were subsequently removed from the model. When controlled for race and age, frequency of private prayer and total religiosity score remained significantly and inversely correlated with the SS/SL polymorphism of the SLC6A4 gene (Table 3). Due to previous literature documenting relationships between religiosity and race, a race $\mathrm{X}$ religiosity interaction term was added to each model. Both frequency of private prayer and total religiosity score showed significant interactions with race such that non-whites with higher religiosity were less likely to have an $S S$ or $S L$ genotype.

In models controlling for demographics, most religious variables were significantly and inversely related to illegal drug use. The only exception was religious experience, which showed a borderline significant bivariable correlation but became non-significant when demographics were controlled. Adding SLC6A4 genotype SS/SL failed to reduce the effect of any religious variable on illegal drug use. However, the genotype itself was significantly and inversely related to illegal drug use, such that the presence of an $S$ allele ( $S S$ or $S L$ ) was protective against drug use ( $\mathrm{OR}=0.82[95 \% \mathrm{CI}=0.69-0.98])$. In models including religious attendance, religious importance, prayer, and total religiosity, both the religiosity variable and SLC6A4 genotype maintained significance (data not shown). Addition of depression and delinquency to each model revealed that these 
variables also significantly predicted drug use, although this addition did not alter the effect of the religious variables or the genome. No interactions between religiosity variables and genotype were significant in these models. Thus, multivariable modeling confirmed religiosity and genotype as independent predictors of illegal drug use with no evidence of mediation or moderation.

\section{Discussion}

\subsection{Meaning of Findings}

Our original hypotheses were that measures of religiosity/spirituality (R/S) would be inversely related to drug use, that R/S would correlate with the presence of polymorphisms of the SLC6A4 gene, that drug use would correlate with the presence of the SLC6A4 polymorphism, and that the SLC6A4 genotype would at least partially mediate relationships between $\mathrm{R} / \mathrm{S}$ and illicit drug use. The findings here provided support for the first three hypotheses only.

Presence of one or two copies of the $S$ allele of SCL6A4 gene was associated with lower levels of religious involvement (i.e., religious individuals were more likely to have the $L L$ genotype). For some religious measures this effect appeared to be explained by race and age (except for frequency of private prayer and total religiosity/spirituality scores). Interactions between race and frequency of private prayer or total religiosity/spirituality score indicated that the more religious non-white respondents were especially less likely to have the $L L$ (vs. the SL/SS) genotype. These relationships are reasonable in light of previous research on race, religiosity, depression, and SLC6A4 genotype. Associations between the $S$ allele of the serotonin transporter promoter region and depressive illness and anxious personality traits have been known for many years (Risch et al., 2009). At the same time, religiosity has been shown to relate inversely to depressive symptoms (Koenig et al., 1992) and to recovery from depression (Koenig et al., 1998). Religiosity has also been found to be more common in African-American populations (Chatters et al., 2009). Therefore it is not surprising to find the interaction between religiosity and non-white race in their association with the SLC6A4 genotype.

We also found that the SLC6A4 genotype was related to use of illicit drugs. Our analyses found that drug use was less common among those with the $S$ allele. While most literature about 5-HTTLPR implicates the $S$ allele in pathological processes, heterogeneity in studies of substance abuse is not uncommon. The bulk of the literature addresses alcoholism. However, there are many studies of SLC6A4 genotype and cigarette smoking, or street drugs such as heroin, cocaine, and MDMA. None of these subfields have come to a consensus about how this gene relates to use of illicit drugs. With regard to the risk of substance abuse, various studies have found the S allele decreases the risk (Laucht et al., 2009; Kweon et al., 2005; Chu et al., 2009), increases the risk (Gerra et al., 2004; Kogan et al., 2010; Merenakk et al., 2011; Lichtermann et al., 2000; Matsushita et al., 2001), or is unrelated (Gelernter et al., 1997; van der Zwaluw et al., 2011; Kranzler et al., 2002).

This study supports the hypothesis that the $S$ allele of SLC6A4 decreases the risk of drug use. It may be that the increased anxiety associated with having the $S$ allele is protective against drug use because those with this polymorphism wish to avoid the associated adverse social consequences. This possibility fits well with recent understanding of the $\mathrm{S}$ allele as conveying hyper-vigilance, which can have negative or positive consequences depending on context (Homberg \& Lesch, 2011).

\subsection{Limitations}

Several factors limit the generalizability of these results. Foremost, is that this analysis is preliminary since no statistical correction was made for paired data or for the clustered sampling method. Furthermore, we acknowledged that many factors that may relate to drug abuse, such as availability, peer deviance, and parental monitoring, were not included in the analysis. The strengths of this study, however, are the large sample size and detailed measures of religious/spiritual involvement collected.

\subsection{Conclusion}

To our knowledge, this is the first study to examine the relationship between polymorphisms of the serotonin transporter gene, religious involvement, and drug use. We found that there was a relationship between the $S$ allele, measures of religiosity/spirituality, and illegal drug use. This suggests that religious/spiritual involvement is an important factor to consider in future research that examines relationships between genetic factors and drug use.

Perhaps the most novel finding from the study is the relationship between religious/spiritual involvement and polymorphisms of the serotonin transporter gene, i.e., the $L L$ genotype. Further study is needed to replicate this association. If confirmed, this discovery may help to explain biological mechanisms underlying religion/health relationships of all types. Such knowledge could pave the way to novel prevention and treatment strategies. 
Table 1. Correlation matrix of all study variables

\begin{tabular}{|c|c|c|c|c|c|c|c|c|c|c|c|c|}
\hline & Gend & Age & Par Ed & Ill Drug & Depress & Deliq & Atten & Import & Pray & Sp Ex & Tot Sp & SCL6A4 \\
\hline Race & 0.01 & 0.03 & $0.04 *$ & $0.13^{@}$ & $-.09^{@}$ & $-.08^{@}$ & $-.14^{@}$ & $-.20^{@}$ & $-.19^{@}$ & $-.08^{\&}$ & $-.20^{@}$ & $0.08^{@}$ \\
\hline Gender & --- & 0.04 & $0.06^{\wedge}$ & $0.11^{@}$ & $-.10^{@}$ & $0.10^{@}$ & $-.09^{@}$ & $-.09^{@}$ & $-.17^{@}$ & $-.05^{*}$ & $-.13^{@}$ & 0.03 \\
\hline Age & & --- & -.04 & $-.05 *$ & -.00 & 0.00 & -.02 & 0.01 & 0.02 & 0.01 & -.00 & $0.05^{*}$ \\
\hline \multicolumn{3}{|c|}{ Parent education } & --- & 0.04 & $-.14^{@}$ & -.00 & $0.11^{@}$ & $0.06^{\wedge}$ & 0.04 & 0.03 & $0.08^{\&}$ & -.02 \\
\hline \multicolumn{3}{|c|}{ Number of illicit drugs } & & --- & $0.06^{\wedge}$ & $0.12^{@}$ & $-.23^{@}$ & $-.17^{@}$ & $-.14^{@}$ & -.04 & $-.22^{@}$ & -.03 \\
\hline \multicolumn{3}{|c|}{ Depression } & & & --- & $0.06^{\wedge}$ & $-.05 *$ & -.02 & 0.01 & $0.05^{*}$ & -.02 & -.01 \\
\hline \multicolumn{4}{|c|}{ Delinquency } & & & --- & -.04 & -.03 & 0.01 & 0.02 & -.02 & -.01 \\
\hline \multicolumn{4}{|c|}{ Religious attendance } & & & & --- & $0.61^{@}$ & $0.51^{@}$ & $0.39^{@}$ & $0.84^{@}$ & $-.05 *$ \\
\hline \multicolumn{4}{|c|}{ Importance of religion/spirituality } & & & & & --- & $0.69^{@}$ & $0.44^{@}$ & $0.90^{@}$ & $-.05^{*}$ \\
\hline \multicolumn{4}{|c|}{ Prayer } & & & & & & --- & $0.36^{@}$ & $0.83^{@}$ & $-.05^{\wedge}$ \\
\hline \multicolumn{4}{|c|}{ Religious experience } & & & & & & & --- & $0.51^{@}$ & -.04 \\
\hline \multicolumn{4}{|c|}{ Total religiosity/spirituality } & & & & & & & & --- & $-.06^{\wedge}$ \\
\hline
\end{tabular}

Race $=1$ (white), Gender $=1$ (male), SCL6A4=SS/SL (vs. LL)

$* \mathrm{p}<0.05,{ }^{\wedge} \mathrm{p}<0.01,{ }^{\&} \mathrm{p}<0.001,{ }^{\circledR} \mathrm{p}<0.0001$

Table 2. Uncontrolled associations between SLC6A4 genotype and religious/spirituality measures

\begin{tabular}{|c|c|c|c|c|}
\hline & LL alleles & S/L or SS alleles & $t / x^{2}$ value & $\mathrm{p}$ \\
\hline $\begin{array}{l}\text { Religious attendance } \\
\text { (mean, SD) }\end{array}$ & $3.09(3.29)$ & $2.79(3.06)$ & 2.21 & 0.03 \\
\hline $\begin{array}{l}\text { Importance of religion/ } \\
\text { spirituality (mean, SD) }\end{array}$ & $6.25(3.09)$ & $5.93(3.04)$ & 2.51 & 0.01 \\
\hline $\begin{array}{l}\text { Frequency of prayer } \\
(\text { mean, SD) }\end{array}$ & $3.95(2.54)$ & $3.67(2.54)$ & 2.64 & $<0.01$ \\
\hline Religious experience & $31 \%$ & $27 \%$ & 4.01 & 0.045 \\
\hline $\begin{array}{l}\text { Total religiosity/spirituality } \\
\text { (mean, SD) }\end{array}$ & $13.62(7.86)$ & $12.67(7.65)$ & 2.91 & $<0.005$ \\
\hline
\end{tabular}

Table 3. Correlations of religiosity to SLC6A4 (SS/SL) controlled for demographics, and significance of the race $\mathrm{x}$ religiosity interaction term in each model

\begin{tabular}{lll}
\hline & $\begin{array}{l}\text { Controlled for } \\
\text { Race \& Age } \\
(\beta)\end{array}$ & $\begin{array}{l}\text { Race x Religiosity } \\
\text { Interaction } \\
(\beta)\end{array}$ \\
\hline Religious attendance & $0.02^{\mathrm{t}}$ & 0.01 \\
Importance of religion/spirituality & $0.03^{\mathrm{t}}$ & $0.03^{\mathrm{t}}$ \\
Prayer & $0.04^{*}$ & $0.05^{* *}$ \\
Religious experience & $-0.09^{\mathrm{t}}$ & -0.03 \\
Total religiosity score & $0.01^{*}$ & $0.01 *$ \\
\hline
\end{tabular}

${ }^{\mathrm{t}} 0.05 \leq \mathrm{p} \leq 0.10, * \mathrm{p}<0.05, * * \mathrm{p}<0.01$

\section{References}

Atmaca, M., Onalan, E., Yildirim, H., Yuce, H., Koc, M., Korkmaz, S., \& Mermi, O. (2011). Serotonin transporter gene polymorphism implicates reduced orbito-frontal cortex in obsessive-compulsive disorder. Journal of Anxiety Disorders, 25(5), 680-685. http://dx.doi.org/10.1016/j.janxdis.2011.03.002

Beaver, K. M., Gibson, C. L., Jennings, W. G., \& Ward, J. T. (2009). A gene X environment interaction between DRD2 and religiosity in the prediction of adolescent delinquent involvement in a sample of males. Biodemography \& Social Biology, 55(1), 71-81. http://dx.doi.org/10.1080/19485560903054689

Brown, G. W., \& Harris, T. O. (2008). Depression and the serotonin transporter 5-HTTLPR polymorphism: a review and a hypothesis concerning gene-environment interaction. Journal of Affective Disorders, 111(1), 1-12. http://dx.doi.org/10.1016/j.jad.2008.04.009 
Calati, R., De Ronchi, D., Bellini, M., \& Serretti, A. (2011). The 5-HTTLPR polymorphism and eating disorders: a meta-analysis. International Journal of Eating Disorders, 44(3), 191-199. http://dx.doi.org/10.1002/eat.20811.

Caspi, A., Sugden, K., Moffitt, T. E., Taylor, A., Craig, I. W., Harrington, H., McClay, J., Milll, J., Martin, J., Braithwaite, A., \& Poulton, R. (2003). Influence of life stress on depression: moderation by a polymorphism in the 5-HTT gene. Science, 301(5631), 386-389. http://dx.doi.org/ 10.1126/science.1083968

Chatters, L. M., Taylor, R. J., Bullard, K. M., \& Jackson, J. S. (2009). Race and ethnic differences in religious involvement: African Americans, Caribbean Blacks and Non-Hispanic Whites. Ethnic and Racial Studies, 32(7), 1143-1163. http://dx.doi.org/10.1080/01419870802334531

Chu, S. L., Xiao, D., Wang, C., \& Jing, H. (2009). Association between 5-hydroxytryptamine transporter gene-linked polymorphic region and smoking behavior in Chinese males. Chinese Medical Journal (Engl), 122(12), 1365-1368.

Dew, R. E., Daniel, S. S., Armstrong, T. D., Goldston, D. B., Triplett, M. F., \& Koenig, H. G. (2008). Religion/spirituality and adolescent psychiatric symptoms: A review. Child Psychiatry \& Human Development, 39(4), 381-398. http://dx.doi.org/10.1007/s10578-007-0093-2.

Edlund, M. J., Harris, K. M., Koenig, H. G., Han, X., Sullivan, G., \& Mattox, R. (2010). Religiosity and decreased risk of substance use disorders: is the effect mediated by social support or mental health status? Social Psychiatry \& Psychiatric Epidemiology, 45(8), 827-836. http://dx.doi.org/10.1007/s00127-009-0124-3

Gelernter, J., Kranzler, H., \& Cubells, J. F. (1997). Serotonin transporter protein (SLC6A4) allele and haplotype frequencies and linkage disequilibria in African- and European-American and Japanese populations and in alcohol-dependent subjects. Human Genetics, 101(2), 243-246. http://dx.doi.org/10.1007/s004390050624

George, L. K., Ellison, C. G., \& Larson, D. B. (2002). Explaining the relationships between religious involvement and health. Psychological Inquiry, 13(3), 190-200. http://dx.doi.org/10.1207/S15327965PLI1303_04

Gerra, G., Garofano, L., Santoro, G., Bosari, S., Pellegrini, C., \& Zaimovic, A. (2004). Association between low-activity serotonin transporter genotype and heroin dependence: Behavioral and personality correlates. American Journal of Medical Genetics, Part B: Neuropsychiatric Genetics, 126B(1), 37-42. http://dx.doi.org/10.1002/ajmg.b.20111

Guo, G., North, K., \& Choi, S. (2006). DRD4 gene variant associated with body mass: the National Longitudinal Study of Adolescent Health. Human Mutations, 27(3), 236-241. http://dx.doi.org/10.1002/humu.20282

Homberg, J. R., \& Lesch, K. P. (2011). Looking on the bright side of serotonin transporter gene variation. Biological Psychiatry, 69(6), 513-519. http://dx.doi.org/10.1016/j.biopsych.2010.09.024

Karg, K., Burmeister, M., Shedden, K., \& Sen, S. (2011). The serotonin transporter promoter variant (5-HTTLPR), stress, and depression meta-analysis revisited: Evidence of genetic moderation. Archives of General Psychiatry, 68(5), 444-454. http://dx.doi.org/10.1001/archgenpsychiatry.2010.189.

Kendler, K. S., \& Myers, J. (2009). A developmental twin study of church attendance and alcohol and nicotine consumption: a model for analyzing the changing impact of genes and environment. American Journal of Psychiatry, 166(10), 1150-1155. http://dx.doi.org/10.1176/appi.ajp.2009.09020182

Koenig, H. G., Cohen, H. J., Blazer, D. G., Pieper, C., Meador, K. G., Shelp, F., Goli, V., \& DiPasquale, R. (1992). Religious coping and depression in elderly hospitalized medically ill men. American Journal of Psychiatry, 149(12), 1693-1700.

Koenig, H. G., George, L. K., \& Peterson, B. L. (1998). Religiosity and remission of depression in medically ill older patients. American Journal of Psychiatry, 155(4), 536-542.

Koenig, H. G., King, D. E., \& Carson, V. B. (2012). Handbook of religion and health ( $2^{\text {nd }}$ ed.). New York, NY: Oxford University Press

Koenig, L. B., McGue, M., Krueger, R. F., \& Bouchard, T. J., Jr. (2007). Religiousness, antisocial behavior, and altruism: genetic and environmental mediation. Journal of Personality, 75(2), 265-290. http://dx.doi.org/10.1111/j.1467-6494.2007.00439.x

Kogan, S. M., Beach, S. R., Philibert, R. A., Brody, G. H., Chen, Y. F., \& Lei, M. K. (2010). 5-HTTLPR status moderates the effect of early adolescent substance use on risky sexual behavior. Health Psychology, 29(5), 471-476. http://dx.doi.org/10.1037/a0020594 
Kranzler, H., Lappalainen, J., Nellissery, M., \& Gelernter, J. (2002). Association study of alcoholism subtypes with a functional promoter polymorphism in the serotonin transporter protein gene. Alcohol \& Clinical Experimental Research, 26(9), 1330-1335. http://dx.doi.org/10.1111/j.1530-0277.2002.tb02675.x

Kweon, Y. S., Lee, H. K., Lee, C. T., Lee, K. U., \& Pae, C. U. (2005). Association of the serotonin transporter gene polymorphism with Korean male alcoholics. Journal of Psychiatric Research, 39(4), 371-376. http://dx.doi.org/10.1016/j.jpsychires.2004.10.005

Laucht, M., Treutlein, J., Schmid, B., Blomeyer, D., Becker, K., \& Buchmann, A. F. (2009). Impact of psychosocial adversity on alcohol intake in young adults: moderation by the LL genotype of the serotonin $\begin{array}{lllll}\text { transporter } & \text { polymorphism. } & \text { Biological } & \text { Psychiatry, } & 66(2),\end{array}$ http://dx.doi.org/10.1016/j.biopsych.2009.02.010.

Lichtermann, D., Hranilovic, D., Trixler, M., Franke, P., Jernej, B., \& Delmo, C. D. (2000). Support for allelic association of a polymorphic site in the promoter region of the serotonin transporter gene with risk for alcohol

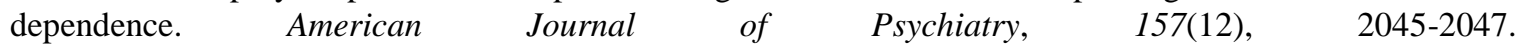
http://dx.doi.org/10.1176/appi.ajp.157.12.2045

Matsushita, S., Yoshino, A., Murayama, M., Kimura, M., Muramatsu, T., \& Higuchi, S. (2001). Association study of serotonin transporter gene regulatory region polymorphism and alcoholism. American Journal of Medical Genetics, 105(5), 446-450. http://dx.doi.org/10.1002/ajmg.1405

Merenakk, L., Maestu, J., Nordquist, N., Parik, J., Oreland, L., Loit, H.M., \& Harro, J. (2011). Effects of the serotonin transporter (5-HTTLPR) and alpha2A-adrenoceptor (C-1291G) genotypes on substance use in children and adolescents: a longitudinal study. Psychopharmacology (Berl), 215(1), 13-22. http://dx.doi.org/10.1007/s00213-010-2109-z

Michalak, L., Trocki, K., \& Bond, J. (2007). Religion and alcohol in the U.S. National Alcohol Survey: How important is religion for abstention and drinking? Drug and Alcohol Dependence, 87(2-3), 268-280. http://dx.doi.org/10.1177/002204260803800308

Minelli, A., Bonvicini, C., Scassellati, C., Sartori, R., \& Gennarelli, M. (2011). The influence of psychiatric screening in healthy populations selection: a new study and meta-analysis of functional 5-HTTLPR and rs25531 polymorphisms and anxiety-related personality traits. BMC Psychiatry, 11(50). http://dx.doi.org/10.1186/1471-244X-11-50

Nilsson, K. W., Damberg, M., Ohrvik, J., Leppert, J., Lindstrom, L., \& Anckarsater, H. (2007). Genes encoding for AP-2beta and the serotonin transporter are associated with the personality character spiritual acceptance. Neuroscience Letters, 411(3), 233-237. http://dx.doi.org/10.1016/j.neulet.2006.10.051

Risch, N., Herrell, R., Lehner, T., Liang, K., Eaves, L., Hoh, J., Griem, A., Kovacs, M., Ott, J., \& Merikangas, K. R. (2009). Interaction between the serotonin transporter gene (5-HTTLPR), stressful life events, and risk of depression: a meta-analysis. Journal of the American Medical Association, 301(23), 2462-2471. http://dx.doi.org/10.1001/jama.2009.878.

Roberts, R. E., \& Vernon, S. W. (1983). The Center for Epidemiologic Studies Depression Scale: Its use in a community sample. American Journal of Psychiatry, 140(1), 41-46.

Timberlake, D., Rhee, S.H., Haberstick, B., Hopfer, C., Ehringer, M., \& Lessem, J. (2006). The moderating effects of religiosity on the genetic and environmental determinants of smoking initiation. Nicotine \& Tobacco Research, 8(1), 123-133. http://dx.doi.org/10.1080/14622200500432054

Vance, T., Maes, H. H., \& Kendler, K. S. (2010). Genetic and environmental influences on multiple dimensions of religiosity: a twin study. Journal of Nervous and Mental Disease, 198(10), 755-761. http://dx.doi.org/10.1097/NMD.0b013e3181f4a07c

van der Zwaluw, C. S., Kuntsche, E., \& Engels, R. C. (2011). Risky alcohol use in adolescence: the role of genetics (DRD2, SLC6A4) and coping motives. Alcohol \& Clinical Experimental Research, 35(4), 756-764. http://dx.doi.org/10.1111/j.1530-0277.2010.01393.x

\section{(cc) $\mathrm{BY}$}

This work is licensed under a Creative Commons Attribution 3.0 License. 